\title{
Reproductive System Findings Derived Flag
}

National Cancer Institute

\section{Source}

National Cancer Institute. Reproductive System Findings Derived Flag. NCI Thesaurus.

Code C117652.

An indication or description that reproductive system findings data is a derived value. 